\title{
Inhibitory Effect of Alpha-Mangostin on Adhesion of Candida albicans to Denture Acrylic
}

\author{
Ruchadaporn Kaomongkolgit, ${ }^{1, *}$ and Kusuma Jamdee ${ }^{2}$ \\ ${ }^{1}$ Department of Oral Diagnosis, Faculty of Dentistry, Naresuan University, Phitsanulok 65000, Thailand \\ ${ }^{2}$ Dental Science Research Center, Faculty of Dentistry, Naresuan University, Phitsanulok 65000, Thailand
}

\begin{abstract}
Objective: Candida-associated denture stomatitis is a very common disease affecting denture wearers. It is characterized by the presence of yeast biofilm on the denture, primarily associated with C. albicans. The investigation of agents that can reduce $C$. albicans adhesion may represent a significant advancement in the prevention and treatment of this disease. This study aims to investigate the effect of alpha-mangostin on the in vitro adhesion of C. albicans to denture acrylic and germ tube formation by $C$. albicans and to compare its activity with clotrimazole which is a topical antifungal agent commonly used for the treatment of Candida-associated denture stomatitis. Materials and Methodology: Alphamangostin was extracted by thin layer chromatography. The effect of alpha-mangostin on adhesion of $C$. albicans to denture acrylic was determined by using a colorimetric tetrazolium assay and germ tube formation by $C$. albicans was determined by using the counting chamber. Results: A significant reduction of C. albicans adhesion to denture acrylic was evident after exposure to $2,000 \mu \mathrm{g} / \mathrm{ml}$ of alpha-mangostin for only $15 \mathrm{~min}$. In addition, the $2,000 \mu \mathrm{g} / \mathrm{ml} \mathrm{of} \mathrm{the} \mathrm{alpha-}$ mangostin-treated $C$. albicans had a reduced ability for germ tube formation. These inhibitory effects of alpha-mangostin were as effective as clotrimazole. Conclusion: Alpha-mangostin has antifungal property against $C$. albicans by inhibiting the adhesion to denture acrylic and germ tube formation in vitro. These results suggest the potential application of alphamangostin as a topical medication or a natural oral hygiene product for treatment of Candida-associated denture stomatitis.
\end{abstract}

Keywords: Adhesion, alpha-mangostin, Candida albicans, denture acrylic, denture stomatitis, germ tube formation.

\section{INTRODUCTION}

Candida-associated denture stomatitis is a very common disease affecting denture wearers, which occurs in up to 65$70 \%$ of denture wearers $[1,2]$. It usually manifests as an erythematous and edematous area of the mucosa in contact with the fitting surface of the denture [3]. This disease is characterized by the presence of yeast biofilm on the denture, primarily associated with $C$. albicans, which has been shown to be the principal Candida species accountable for inflammatory pathology $[4,5]$. Clinical studies have shown that $C$. albicans is not only able to adhere to mucosal surface, but also acrylic resin denture and produce a complex biofilm $[6,7]$. The presence of the biofilm on the denture is critical to the development of the observed clinical entity of Candida-associated denture stomatitis [8]. Despite treating with antifungal therapy, infection can be re-established soon after treatment ceases, suggesting that the denture act as a reservoir for C. albicans to continually re-infect the mucosal surface [7]. As the adhesion of $C$. albicans to the denture acrylic is a prerequisite for colonization and biofilm formation [9], the investigation of novel antifungal agents, which can reduce $C$. albicans adhesion, will represent a significant advance in the prevention and treatment of Candidaassociated denture stomatitis.

\footnotetext{
*Address correspondence to this author at the Department of Oral Diagnosis, Faculty of Dentistry, Naresuan University, 99 Moo9 PhitsanulokNakornsawan Road, Amphor Mueng, Phitsanulok 65000, Thailand; Tel: +665 966065; Fax: +665 966053; E-mail: ruchadapornk@yahoo.com
}

Natural products have been proved to be an alternative to synthetic chemical substances and many plant extracts exert antifungal activity [10-12], including alpha-mangostin [13]. Alpha-mangostin is an antimicrobial xanthone isolated from Garcinia mangostana Linn. (mangosteen). The pericarp of mangosteen fruit has been used as traditional medicine for treatment of skin infections, wounds, and diarrhea by Southeast Asians for many years $[14,15]$. The results from our previous study revealed that alpha-mangostin was active against $C$. albicans, with the minimum inhibitory concentration (MIC) and minimum fungicidal concentration (MFC) at 1 and $2 \mathrm{mg} / \mathrm{ml}$, respectively [13].

In order to provide the information on the use of alphamangostin as a topical medication or a natural oral hygiene product, we determined the effect of alpha-mangostin on the in vitro adhesion of $C$. albicans to denture acrylic and germ tube formation by $C$. albicans. Its activity was compared with clotrimazole, which is a topical antifungal agent commonly used for treatment of Candida-associated denture stomatitis.

\section{MATERIALS AND METHODOLOGY}

\section{Preparation of Alpha-Mangostin}

Crude extract and purified alpha-mangostin were prepared based on methods in previous articles [13, 16, 17]. Briefly, dried and ground mangosteen pericarps were macerated in hexane for $24 \mathrm{~h}$ to remove non-polar substances. The resulting marc was subsequently macerated in ethyl acetate 
for $24 \mathrm{~h}$. The ethyl acetate extract obtained was then recrystallized, and ground into power. The yield of mangosteen crude extract from the dried pericarp was approximately $3 \%$ (w/w). To obtain alpha-mangostin, the crude extract was chromatographed on a silica gel column, and eluted with increasing percentages of ethyl acetate in hexane (0-25\%). A hexane-ethyl acetate $(4: 1)$ elute was selected based on the thin layer chromatography profile. The selected fraction was further identified as alpha-mangostin by using mass spectrometry, nuclear magnetic resonance spectroscopy and a Gallenkamp melting point apparatus. The yield of alphamangostin from the dried pericarp was approximately $0.4 \%$ (w/w). The stock solution of alpha-mangostin was dissolved in dimethysulfoxide (DMSO) and sterilized by filtration through $0.2 \mu \mathrm{m}$ disc filters.

\section{Antifungal Agent and $C$. albicans Culture}

Clotrimazole powder (Continental-Pharm Co. LTD., Bangkok, Thailand) was prepared as concentrated stock solution in DMSO. The final concentration of prepared clotrimazole stock solution was $48 \mu \mathrm{g} / \mathrm{ml}$. C. albicans strain ATCC 90028 used in this study was obtained from the microbiology laboratory of the Department of Medical Sciences, Ministry of Public Health, Thailand. The working stock cultures of $C$. albicans were maintained on Sabouraud dextrose agar slants (Becton, Dickinson and Company, Sparks, MD, USA) at $4^{\circ} \mathrm{C}$ until use. Candida cells to be tested were grown in Sabouraud dextrose broth for $24 \mathrm{~h}$ at $37^{\circ} \mathrm{C}$.

\section{Preparation of Denture Acrylic}

The acrylic strips were prepared based on the method in a previous report [18]. Self-polymerizing acrylic powder and monomer liquid were mixed according to the manufacturer's instruction (Leone Spa, Sesto Fiorentino, Italy). The mixture was placed between two glass slides $(2.5 \mathrm{~cm} \times 7.5 \mathrm{~cm})$, which were fixed at both ends with two clips. Then the acrylic was polymerized in a hydroflask at $50^{\circ} \mathrm{C}$ for $5 \mathrm{~min}$ afterwards, the formed transparent acrylic sheet was stripped from the slides and cut into strips $(5 \mathrm{~mm} \times 5 \mathrm{~mm}$ square and $0.4 \mathrm{~mm}$ thick). These strips were immersed in distilled water for 1 week to leach excess monomer then dipped into $70 \%$ alcohol for $1 \mathrm{~min}$ and washed three times in distilled water. After that the strips were ultrasonicated for $20 \mathrm{~min}$ at $60^{\circ} \mathrm{C}$. Finally, the strips were sealed in the petri dishes for sterilization in autoclave for $15 \mathrm{~min}$ at $1.2 \mathrm{bar}, 121^{\circ} \mathrm{C}$, then the strips were dried overnight in a hot air oven at $50^{\circ} \mathrm{C}$ prior to use in adhesion assay.

\section{Effect of Alpha-Mangostin on Adhesion of $C$. albicans to Denture Acrylic}

The adhesion assay was modified from the previous reports [18, 19]. $0.2 \mathrm{ml}$ of different alpha-mangostin and clotrimazole concentrations $(1 \times \mathrm{MFC}, 2 \times \mathrm{MFC}$ and $4 \times \mathrm{MFC})$ was placed in 48-well plates (Thermo Fisher Scientific, Roskilde, Denmark). Wells containing $0.2 \mathrm{ml}$ of normal saline solution (NSS) served as the negative control. Candida suspension were spectrophotometrically standardized to $10^{8}$ cells $/ \mathrm{ml}$. Then the acrylic strips were placed in the 48 -well plates and $0.2 \mathrm{ml}$ of Candida suspension in Sabouraud dex- trose broth was added to each well, which completely soaked the acrylic strips, and incubated at $37^{\circ} \mathrm{C}$ for $3 \mathrm{~h}$ with agitation at $120 \mathrm{rpm} / \mathrm{min}$. After incubation, the acrylic strips were removed from the wells and washed three times with phosphate buffered saline (PBS) to remove the unattached Candida cells. Then the acrylic strips were placed in the new 48-well plates. The fungal cell viability was determined using a 2,3-bis (2-methoxy-4-nitro-5-sulfo-phenyl)-5-[(phenylamino)-carbonyl]2H-tetrazolium hydroxide (XTT) (Sigma, St. Louis, MO, USA) reduction assay that measures the activity of mitochondrial dehydrogenase. Briefly, XTT solution $(1 \mathrm{mg} / \mathrm{ml})$ was prepared by dissolving XTT powder in PBS, and the solution was filter-sterilized $(0.22 \mu \mathrm{m}$ pore size filter $)$. XTT solution was mixed with freshly prepared menadione solution $(0.4 \mathrm{mM})$ at $20: 1(\mathrm{v} / \mathrm{v})$ immediately prior to the assay. XTT-menadione solution $200 \mu \mathrm{l}$ was transferred to each well, and incubated in the dark for $2 \mathrm{~h}$ at $37^{\circ} \mathrm{C}$. After the incubation, the colored supernatant $(100 \mu \mathrm{l})$ was transferred to new microtiter plates, and the optical density of the supernatant was measured at $490 \mathrm{~nm}$ with a microtiter plate reader (Bio-Rad Laboratories Inc., Hercules, CA, USA). All experiments were performed on three separate occasions with triplicate determinations on each occasion.

To determine the minimum duration of alpha-mangostin in reducing $C$. albicans adhesion to denture acrylic, the alpha-mangostin at the lowest concentration capable of reducing candidal adhesion to denture acrylic as effective as 1xMFC $(20 \mu \mathrm{g} / \mathrm{ml})$ of clotrimazole was chosen. Adhesion of C. albicans to denture acrylic was determined after exposure to alpha-mangostin or clotrimazole for $1,15,30,60,120$ and $180 \mathrm{~min}$. All experiments were performed on three separate occasions with triplicate determinations on each occasion.

\section{Effect of Alpha-Mangostin on Germ Tube Formation}

Effect of alpha-mangostin on germ tube formation was performed based on the method in a previous report [20]. The germ tube formation was induced in a medium containing fetal bovine serum (10\% v/v) (Gibco-BRL, Gland Island, NY, USA) as an inducer of germ tube formation. Aliquots of $100 \mu \mathrm{l}$ from Candida suspension $\left(1-5 \times 10^{7}\right.$ viable cell $\left./ \mathrm{ml}\right)$ were incubated in sterile tubes containing Sabouraud dextrose broth medium $(2 \mathrm{ml})$ in the presence of $10 \%$ fetal bovine serum and different alpha-mangostin and clotrimazole concentrations $(1 \times \mathrm{MFC}, 2 \times \mathrm{MFC}$ and $4 \times \mathrm{MFC})$. The contents of the tubes were vigorously mixed and incubated at $37^{\circ} \mathrm{C}$. After $3 \mathrm{~h}$ of incubation, aliquots were taken to count the cell number microscopically. The total cell number and germ tube formation were counted using the counting chamber, and the germ tube formation was expressed as a percentage of cells forming germ tube from the total cell number. All experiments were performed on three separate occasions with triplicate determinations on each occasion.

\section{Statistical Analysis}

All statistical computations were performed by SPSS for Windows software (version 15.0; SPSS Inc., Chicago, IL, USA). Data from adhesion assay and germ tube formation were presented as means and standard error. Differences in the adhesion of $C$. albicans to the denture acrylic and germ tube formation at each group were analyzed by one-way 
Table 1. Adhesion of Candida albicans to denture acrylic following a 3-h exposure to various concentrations of alpha-mangostin and clotrimazole.

\begin{tabular}{|c|c|c|c|c|c|c|c|}
\hline & Control & \multicolumn{3}{|c|}{ Alpha-mangostin $(\mu \mathrm{g} / \mathrm{ml})$} & \multicolumn{3}{|c|}{ Clotrimazole $(\mu \mathrm{g} / \mathrm{ml})$} \\
\hline Reduction in adherence (\%) & 0 & 80.28 & 82.68 & 93.16 & 85.86 & 88.56 & 95.27 \\
\hline
\end{tabular}

* $P<0.05$ compared with control

Table 2. Adhesion of Candida albicans to denture acrylic after exposure to $2,000 \mu \mathrm{g} / \mathrm{ml}$ of alpha-mangostin and $20 \mu \mathrm{g} / \mathrm{ml}$ of clotrimazole at various time intervals.

\begin{tabular}{|c|c|c|c|c|c|}
\hline Time (min) & \multicolumn{3}{|c|}{$\mathrm{OD}_{490}($ mean \pm S.E. $)(\mathrm{n}=9)$} & \multicolumn{2}{|c|}{ Reduction in adherence (\%) } \\
\hline 1 & $0.035 \pm 0.008$ & $0.034 \pm 0.010$ & $0.026 \pm 0.006$ & 2.93 & 25.71 \\
\hline 15 & $0.319 \pm 0.029$ & $0.200 \pm 0.021 *$ & $0.126 \pm 0.025^{*}$ & 37.30 & 60.45 \\
\hline 60 & $0.351 \pm 0.021$ & $0.138 \pm 0.013 *$ & $0.087 \pm 0.012 *$ & 60.48 & 75.18 \\
\hline 120 & $0.386 \pm 0.023$ & $0.127 \pm 0.010^{*}$ & $0.065 \pm 0.007 *$ & 66.98 & 83.17 \\
\hline 180 & $0.507 \pm 0.034$ & $0.010 \pm 0.029 *$ & $0.071 \pm 0.009^{*}$ & 80.28 & 85.86 \\
\hline
\end{tabular}

$* P<0.05$ compared with control

analysis of variance (ANOVA). Statistical significance was defined as $P<0.05$.

\section{RESULTS}

The adhesion values and the percentage reduction in the adhesion of $C$. albicans to denture acrylic following a 3-h exposure to various concentrations of alpha-mangostin and clotrimazole were presented in Table 1. Compared with the control, a significant reduction of $C$. albicans adhesion to denture acrylic was observed after exposure to alphamangostin at concentration of $\geq 2,000 \mu \mathrm{g} / \mathrm{ml}(P<0.05)$. Clotrimazole, an antifungal drug used as positive control in this study, strongly inhibited the adhesion of $C$. albicans to denture acrylic. A significant reduction of $C$. albicans adhesion to denture acrylic was observed after exposure to clotrimazole at concentration of $\geq 20 \mu \mathrm{g} / \mathrm{ml}$ when compared with control $(P<0.05)$.

The alpha-mangostin at a concentration of $2,000 \mu \mathrm{g} / \mathrm{ml}$ was capable of significantly reducing candida adhesion to denture acrylic as effective as $20 \mu \mathrm{g} / \mathrm{ml}$ of clotrimazole. Thus, $2,000 \mu \mathrm{g} / \mathrm{ml}$ of alpha-mangostin was used to determine the minimum duration of alpha-mangostin in reducing $C$. albicans adhesion to denture acrylic. The adhesion and the percentage reduction in the adhesion of $C$. albicans to denture acrylic after exposure to $2,000 \mu \mathrm{g} / \mathrm{ml}$ of alphamangostin and $20 \mu \mathrm{g} / \mathrm{ml}$ of clotrimazole at various time intervals are presented in Table 2 . Compared to the control, a significant reduction of $C$. albicans adhesion to denture acrylic was observed after exposure to $2,000 \mu \mathrm{g} / \mathrm{ml}$ of alpha- mangostin for only $15 \mathrm{~min}(P<0.05)$. The effect of alphamangostin and clotrimazole on germ tube formation by $C$. albicans was also investigated. As shown in Table $\mathbf{3}$, the suppression of germ tube formation was significant in comparison with that of the control $(P<0.05)$.

\section{DISCUSSION}

The most prevalent oral infection involving Candida is Candida-associated denture stomatitis [21]. Denture wearing is the major predisposing factor, especially in cases the denture is not sufficiently cleansed or is retained overnight in the oral cavity. Under these conditions, the dormant area above the upper fitting surface of the denture provides an ideal environment for growth of Candida, which is adept at adhering to denture acrylic. Adherence of Candida to denture acrylic is a crucial first step in the initiation and propagation of Candida-associated denture stomatitis [22].

Several groups of antifungal drugs are currently available for treatment of Candida-associated denture stomatitis. However, the increasing prevalence of drug-resistant $C$. albicans recovered from patients is a major concern worldwide. Therefore, it is necessary to develop new classes of antifungal agents. Among a number of candidate therapeutic agents, plant extracts have recently received an increasing attention. The effects of the medicinal plants claimed to be useful as antifungal agents in the treatment of Candida-associated denture stomatitis were reported [12]. Our previous study revealed that alpha-mangostin was active against $C$. albicans [13]. The present study also demonstrated the antifungal 
Table 3. Germ tube formation by Candida albicans following a 3-h exposure to various concentrations of alpha-mangostin and clotrimazole.

\begin{tabular}{|c|c|c|c|c|c|c|c|}
\hline & Control & \multicolumn{3}{|c|}{ Alpha-mangostin $(\boldsymbol{\mu g} / \mathbf{m l})$} & \multicolumn{3}{|c|}{ Clotrimazole $(\boldsymbol{\mu g} / \mathbf{m l})$} \\
\hline & & $\mathbf{2 , 0 0 0}$ & $\mathbf{4 , 0 0 0}$ & $\mathbf{8 , 0 0 0}$ & $\mathbf{2 0}$ & $\mathbf{4 0}$ & $\mathbf{8 0}$ \\
\hline \hline Number of germ tubes formed/300 yeast (mean \pm S.E.) $(\mathrm{n}=9)$ & $218 \pm 40$ & $120 \pm 30^{*}$ & $108 \pm 50^{*}$ & $71 \pm 20^{*}$ & $120 \pm 60^{*}$ & $101 \pm 30^{*}$ & $78 \pm 70^{*}$ \\
\hline Reduction in germ tube formation (\%) & 0 & 45.03 & 50.27 & 67.56 & 44.67 & 53.53 & 64.32 \\
\hline
\end{tabular}

$* \mathrm{P}<0.05$ compared with control

effect of alpha-mangostin on the in vitro adhesion of $C$. albicans to denture acrylic and germ tube formation by $C$. albicans. The results indicated that a significant reduction of $C$. albicans adhesion to denture acrylic was evident after exposure to $2,000 \mu \mathrm{g} / \mathrm{ml}$ of alpha-mangostin for only $15 \mathrm{~min}$. In addition, the $2,000 \mu \mathrm{g} / \mathrm{ml}$ of the alpha-mangostin-treated C. albicans had a decreased ability for germ tube formation. These inhibitory effects of alpha-mangostin were as effective as clotrimazole. These properties makes it a promising alternative antifungal agent for treatment of Candida-associated denture stomatitis. However, this study design was limited to the examination of one $C$. albicans strain, drug concentrations at $1 \times \mathrm{MFC}, 2 \times \mathrm{MFC}$ and $4 \times \mathrm{MFC}$, and at 6 time intervals. Therefore, it is possible that differences in antifungal activity might be evident if the experiment was conducted using different strains, concentrations, and time intervals. Further studies are required to obtain more understanding on antifungal properties of alpha-mangostin.

The effect of alpha-mangostin on adhesion of C. albicans to denture acrylic was determined by using a colorimetric tetrazolium assay (XTT assay). The XTT assay and other colorimetric methods are considered as valuable tool for examining the behavior of yeast, whether in planktonic or biofilm form. Due to their ease of use, the colorimetric tetrazolium assays are increasingly used to make direct comparisons between Candida isolates, often in the absence of other numerical methods. However, limitations of the XTT assay in studies of Candida growth and metabolism have been reported. First, although tetrazolium assays are valuable for quantitation within a yeast strain, it cannot be assumed that there is necessarily a linear relationship between organism number and colorimetric signal. Second, interstrain comparisons cannot be measured in the absence of detailed standardization, since different strains metabolize substrate with different capabilities. Third, the relationship between the XTT concentration used and the resultant colorimetric signal is not necessarily proportional; valid quantitation can only be performed after the creation of appropriate standard curves for each amount of tetrazolium used. Fourth, while the XTT formazan product readily appears in solution, there can be in some strains a significant amount of retained intracellular product, which only becomes soluble after cell treatment with DMSO. The amount of retained product may vary between different cellular states, e.g., planktonic and biofilm [23].

C. albicans is able to form biofilm on the surfaces of denture acrylic. The formation of Candida biofilms are more resistant to antifungal drugs, resulting in treatment failure $[18,21]$. The process of Candidal adhesion to denture acrylic is complex and involving a number of factors includ- ing poor oral and denture hygiene, low $\mathrm{pH}$ under dentures, high intake of dietary carbohydrates, Candida cell surface mannoprotein, surface structure, properties and composition of denture materials, cell surface hydrophobicity, surface free energy and roughness of the denture acrylic $[18,22]$.

The mechanism of alpha-mangostin for inhibition of Candida adhesion remains undetermined, but it is suggested that it might alter cell surface structures and integrity, resulting in masking of adhesins on Candida cell [24]. In addition, alpha-mangostin-treated $C$. albicans also demonstrated a decreased capacity to produce germ tube, which might be related to the effect of alpha-mangostin on Candida cell wall structure that it may interfere with any changes in cell surface hydrophobicity. These alterations might result in a shift in the free energy of interaction of the cell with the denture acrylic surface, thereby reducing Candida adhesion [18]. However, further in vitro and in vivo studies are required to clarify its mechanism.

Regarding the toxic effects of alpha-mangostin, previous in vitro and in vivo studies have demonstrated low toxicity of the mangosteen pericarp extract and its active components $[13,25-28]$. The extract from mangosteen pericarp was not toxic to human gingival fibroblast culture for up to $48 \mathrm{~h}$ at the concentration $200 \mu \mathrm{g} / \mathrm{ml}$ [25]. In addition, alphamangostin at $4000 \mu \mathrm{g} / \mathrm{ml}$ was not toxic to human gingival fibroblast culture for $480 \mathrm{~min}$ [13]. Furthermore, in animal study, alpha-mangostin was administered orally to rats at a high dose ( $1.5 \mathrm{~g} / \mathrm{kg}$ body weight) to test its hepatotoxicity. It was found that after $12 \mathrm{~h}$, level of serum glutamate oxaloacetate transaminase (SGOT) and serum glutamate pyruvate transaminase (SGPT) activities in study groups were less than those of paracetamol given at the same dose [26]. Another study used alpha-mangostin given to rats at an oral dose of $200 \mathrm{mg} / \mathrm{kg}$ body weight per day, and did not observe any toxicity after 6 days of treatment [27]. In human clinical trials, herbal mouthwash containing the pericarp extract of Garcinia mangostana was used in subjects with chronic gingivitis up to 2 weeks and no local irritation or side effects were observed [28]. According to its antifungal activity and low toxicity, alpha-mangostin might be beneficial for Candida-associated denture stomatitis therapy. However, because the effective concentration of alpha-mangostin against C. albicans in this study was relatively high, it might be toxic in a clinical use. Therefore, we suggest a new potential application of alpha-mangostin as a denture cleanser or disinfecting agent against $C$. albicans and the clinical significance of these in vitro results should be determined by clinical trials. In conclusion, this study indicated that alphamangostin has antifungal property against $C$. albicans by inhibiting Candida adhesion to denture acrylic and germ 
tube formation in vitro. These results suggest the potential application of alpha-mangostin as promising antifungal agent for treatment of Candida-associated denture stomatitis.

\section{CONFLICT OF INTEREST}

The authors confirm that this article content has no conflict of interest.

\section{ACKNOWLEDGEMENTS}

This work was supported by the Faculty of Dentistry, Naresuan University (Research grants from income of fiscal year 2014, the grant number: R2557C106). The authors would like to thank Dr. Chalatip Chompunud Na Ayudhya, instructor of Faculty of Dentistry, for valuable discussion and Mr. Arthur John Pollock, instructor of Faculty of Humanities, Naresuan University, for editing the manuscript.

\section{REFERENCES}

[1] Gendreau L, Loewy ZG. Epidemiology and etiology of denture stomatitis. J Prosthodont 2011; 20: 251-60.

[2] Budtz-Jorgensen E, Stenderup A, Grabowski M. An epidemiologic study of yeasts in elderly denture wearers. Community Dent Oral Epidemiol 1975; 3: 115-9.

[3] Farah CS, Lynch N, McCullough MJ. Oral fungal infections: an update for the general practitioner. Aust Dent J 2010; 55: 48-54.

[4] Salerno C, Pascale M, Contaldo M, et al. Candida-associated denture stomatitis. Med Oral Patol Oral Cir Bucal 2011; 16: e139-43.

[5] Pereira-Cenci T, Del Bel Cury AA, Crielaard W, Ten Cate JM. Development of Candida-associated denture stomatitis: new insights. J Appl Oral Sci 2008; 16: 86-94.

[6] Ganguly S, Mitchell AP. Mucosal biofilms of Candida albicans. Curr Opin Microbiol 2011; 14: 380-5.

[7] Radford DR, Challacombe SJ, Walter JD. Denture plaque and adherence of Candida albicans to denture-base materials in vivo and in vitro. Crit Rev Oral Biol Med 1999; 10: 99-116.

[8] Williams DW, Kuriyama T, Silva S, Malic S, Lewis MA. Candida biofilms and oral candidosis: treatment and prevention. Periodontology $20002011 ; 55: 250-65$.

[9] Cate TJM, Klis FM, Pereira-Cenci T, Crielaard W, de Groot PW. Molecular and cellular mechanisms that lead to Candida biofilm formation. J Dent Res 2009; 88: 105-15.

[10] Rajeshkumar R, Sundararaman M. Emergence of Candida spp. and exploration of natural bioactive molecules for anticandidal therapystatus quo. Mycoses 2012; 55: e60-73.

[11] Marcos-Arias C, Eraso E, Madariaga L, Quindos G. In vitro activities of natural products against oral Candida isolates from denture wearers. BMC Complement Altern Med 2011; 11: 119.
[12] Casaroto AR, Lara VS. Phytomedicines for Candida-associated denture stomatitis. Fitoterapia 2010; 81:323-8.

[13] Kaomongkolgit R, Jamdee K, Chaisomboon N. Antifungal activity of alpha-mangostin against Candida albicans. J Oral Sci 2009; 51 : 401-6.

[14] Obolskiy D, Pischel I, Siriwatanametanon N, Heinrich M. Garcinia mangostana L.: a phytochemical and pharmacological review. Phytother Res 2009; 23: 1047-65.

[15] Pedraza-Chaverri J, Cardenas-Rodriguez N, Orozco-Ibarra M, Perez-Rojas JM. Medicinal properties of mangosteen (Garcinia mangostana). Food Chem Toxicol 2008; 46: 3227-39.

[16] Kaomongkolgit R, Chaisomboon N, Pavasant P. Apoptotic effect of alpha-mangostin on head and neck squamous carcinoma cells. Arch Oral Biol 2011; 56: 483-90.

[17] Kaomongkolgit R. Alpha-mangostin suppresses MMP-2 and MMP-9 expression in head and neck squamous carcinoma cells. Odontology 2013; 101: 227-32.

[18] Taweechaisupapong S, Klanrit P, Singhara S, Pitiphat W, Wongkham S. Inhibitory effect of Streblus asper leaf-extract on adhesion of Candida albicans to denture acrylic. J Ethnopharmacol 2006; 106: 414-7.

[19] Thaweboon B, Thaweboon S. Effect of Phyllanthus emblica Linn. on Candida adhesion to oral epithelium and denture acrylic. Asian Pac J Trop Med 2011; 4: 41-5.

[20] Bernardes I, Rodrigues FMP, Bacelli GK, Munin E, Alves LP, Costa MS. Aloe vera extract reduces both growth and germ tube formation by Candida albicans. Mycoses 2012; 55: 257-61.

[21] Chandra J, Mukherjee PK, Leidich SD, et al. Antifungal resistance of candidal biofilms formed on denture acrylic in vitro. J Dent Res 2001; 80: 903-8.

[22] He XY, Meurman JH, Kari K, Rautemaa R, Samaranayake LP. In vitro adhesion of Candida species to denture base materials. Mycoses 2006; 49: 80-4

[23] Kuhn DM, Balkis M, Chandra J, Mukherjee PK, Ghannoum MA. Uses and limitations of the XTT assay in studies of Candida growth and metabolism. J Clin Microbiol 2003; 41: 506-8.

[24] Taweechaisupapong S, Choopan T, Singhara S, Chatrchaiwiwatana $\mathrm{S}$, Wongkham S. In vitro inhibitory effect of Streblus asper leafextract on adhesion of Candida albicans to human buccal epithelial cells. J Ethnopharmacol 2005; 96: 221-6.

[25] Torrungruang K, Chutimaworapan S. Effect of mangosteen pericarp extract on cell viability in human gingival fibroblasts. CU Dent J 2006; 29: 75-82.

[26] Sornprasit A, Sripiyarattanakul K, Chuay-Yim P, Tanakittihum P. Pleliminary toxicological study of mangostin. Songklanakarin J Sci Technol 1987; 9: 51-7.

[27] Sampath D, Vijavaraghavan K. Cardioprotective effect of alphamangostin, a xanthone derivative from mangosteen on tissue defense system against isoproterenol-induced myocardial infarction in rats. J Biochem Mol Toxicol 2007; 21: 336-9.

[28] Rassameemasmaung S, Sirikulsathean A, Amornchat C, Hirunrat K, Rojanapanthu P, Gritsanapan W. Effects of herbal mouthwash containing the pericarp extract of Garcinia mangostana $\mathrm{L}$ on halitosis, plaque and papillary bleeding index. J Int Acad Periodontol 2007; 9: 19-25.

Received: July 30, 2015

Revised: August 31, 2015

Accepted: October 08, 2015

(C) Kaomongkolgit and Jamdee; Licensee Bentham Open

This is an open access article licensed under the terms of the (https://creativecommons.org/licenses/by/4.0/legalcode), which permits unrestricted, noncommercial use, distribution and reproduction in any medium, provided the work is properly cited. 